\title{
Clinical Manifestations of Senecavirus A Infection in Neonatal Pigs, Brazil, 2015
}

\author{
Raquel A. Leme, ${ }^{1}$ Thalita E.S. Oliveira, ${ }^{1}$ \\ Brígida K. Alcântara, Selwyn A. Headley, \\ Alice F. Alfieri, Ming Yang, Amauri A. Alfieri
}

We identified new clinical manifestations associated with Senecavirus A infection in neonatal piglets in Brazil in 2015. Immunohistochemical and molecular findings confirmed the association of Senecavirus A with these unusual clinical signs and more deaths. Other possible disease agents investigated were not associated with these illnesses.

Cenecavirus A (SVA), formerly called Seneca Valley

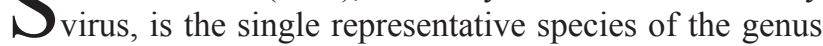
Senecavirus (family Picornaviridae). SVA is a singlestranded, positive-sense, nonenveloped RNA virus with a genome size of $\approx 7.2 \mathrm{~kb}(1)$.

SVA infection was associated with porcine idiopathic vesicular disease (PIVD) in pigs in Canada (2), the United States $(1)$, and Brazil $(3,4)$. The clinical manifestations of PIVD are indistinguishable from those of other vesicular virus infections, including foot-and-mouth disease virus (FMDV), vesicular stomatitis virus, swine vesicular disease virus (SVDV), and vesicular exanthema of swine virus $(2,3)$. These clinical signs include fluid-filled and ruptured vesicles and ulcerative lesions at the coronary band, hooves, and/or snout (1-4). In 2015, we identified new clinical manifestations associated with SVA infections in piglets in Brazil.

\section{The Study}

Since early 2015, increased numbers of deaths were recorded in pig herds from different geographic regions of Brazil. Piglets during their first week of life demonstrated clinical signs such as muscular weakness, lethargy, excessive salivation, cutaneous hyperemia, neurologic manifestations, and diarrhea; some died suddenly. Clinical signs lasted for 3-10 days and then disappeared in piglets that survived.

To determine the cause of these illnesses, we investigated 5 farms (A-E). Pig populations per farm varied from 10,000 to 23,000 animals, and piglet death rates during the first week of life ranged from $20 \%$ to $30 \%$. Ten piglets that died spontaneously were examined (Table 1).

Author affiliations: Universidade Estadual de Londrina, Paraná, Brazil (R.A. Leme, T.E.S. Oliveira, B.K. Alcântara, S.A. Headley, A.F. Alfieri, A.A. Alfieri); National Centre for Foreign Animal Disease, Winnipeg, Manitoba, Canada (M. Yang)
Farms A, B, D, and E had gestating and/or farrowing sows with fluid-filled or ruptured vesicles at the coronary bands, hooves, or snouts; reproductive disorders were not observed. We had identified SVA RNA from sows at farms $A$ and B (3) a week before the onset of clinical manifestations in these piglets.

Routine necropsies of all piglets were conducted soon after death. Tissues were fixed by immersion in $10 \%$ buffered formalin solution and processed for histopathologic evaluation. Selected tissue fragments were used in an immunohistochemical (IHC) assay designed with monoclonal antibodies to detect SVA (5). Duplicate sections of the organs and scrapings from oral vesicles and cutaneous lesions were collected for molecular diagnostics. From piglets at farms $\mathrm{C}$, $\mathrm{D}$, and $\mathrm{E}$, we collected diarrheic fecal samples to investigate the possibility of enteric viruses. We analyzed 81 tissue samples and 6 diarrheic fecal samples during this study by a combination of pathologic and molecular diagnostic methods.

Molecular assays were conducted to identify viruses that might be associated with the reported clinical signs; these included SVA (3); FMDV, vesicular stomatitis virus, and SVDV (6); teschovirus A, sapelovirus A, and enterovirus $\mathrm{G}(7)$; porcine parvovirus (8); and porcine circovirus type 2 (9). Feces and fragments of the small intestine from piglets of farms $\mathrm{C}, \mathrm{D}$, and $\mathrm{E}$ were evaluated for porcine rotavirus species A, B, C (10), and $\mathrm{H}$ (11); porcine epidemic diarrhea virus (12); swine deltacoronavirus (13); and transmissible gastroenteritis virus (12).

Seventeen amplified products were submitted for sequencing. We conducted sequence identity matrix using BioEdit software version 7.1.11 (http://www.mbio.ncsu. edu/bioedit/bioedit.html). A phylogenetic tree based on nucleotide sequences was obtained using MEGA6 software (http://www.megasoftware.net).

The most frequent gross manifestations observed were petechial hemorrhages of the kidney (7 piglets) and ulcerative lesions at the tongue (6 piglets) and coronary bands (4 piglets) (Figure 1, panels A, B). Interstitial pneumonia, the predominant histopathologic alteration, occurred in all the piglets; other frequent lesions were diphtheric glossitis (6 piglets), lymphocytic myocarditis (6 piglets), ballooning degeneration of the transitional epithelium of the urinary bladder (Figure 1, panel C) and the ureters (4 piglets), and lymphoplasmacytic encephalitis (3 piglets).

Consistent SVA IHC staining occurred at the transitional epithelium of the renal pelvis and the urinary bladder

${ }^{1}$ These authors contributed equally to this article. 
Table 1. Geographic locations and other charactereristics of pig farms affected by Senecavirus A, Brazil, 2015

\begin{tabular}{|c|c|c|c|c|c|}
\hline Farm & State/region & $\begin{array}{l}\text { Month of } \\
\text { collection }\end{array}$ & Animal no. & Age, $d$ & Principal clinical manifestations \\
\hline \multirow[t]{2}{*}{ A } & Paraná/Southern Brazil & February & 1 & 2 & Weakness at birth, sudden death at $1-3 \mathrm{~d}$ of age \\
\hline & & & 2 & 1 & \\
\hline B & Paraná/Southern Brazil & February & $\begin{array}{l}3 \\
4\end{array}$ & $\begin{array}{l}2 \\
1\end{array}$ & Weakness at birth, sudden death at $1-3 \mathrm{~d}$ of age \\
\hline $\mathrm{C}$ & Mato Grosso do Sul/Midwest Brazil & March & 5 & 3 & $\begin{array}{c}\text { Cutaneous hyperemia, diarrhea, excessive salivation, } \\
\text { lethargy, death }\end{array}$ \\
\hline $\mathrm{D}$ & Santa Catarina/Southern Brazil & March & 6 & 2 & Acute diarrhea and/or wasting, death \\
\hline \multirow[t]{4}{*}{$\mathrm{E}$} & Santa Catarina/Southern Brazil & July & 7 & 2 & Diarrhea, neurologic manifestations, sudden death \\
\hline & & & 8 & 2 & \\
\hline & & & 9 & 4 & \\
\hline & & & 10 & 5 & \\
\hline
\end{tabular}

(Figure 1, panel D) of 4 piglets; within epithelial cells of the choroid plexus of the cerebrum ( 8 piglets) and the tongue ( 5 piglets); and at the ependymal cells of the choroid plexus, vascular endothelium, and the enterocytes of the villi of the small intestine (2 piglets) (Table 2, http://wwwnc.cdc.gov/ EID/article/22/7/15-1583-T2.htm).

The expected SVA RNA fragment was amplified by reverse transcription PCR from $77.8 \%(63 / 81)$ of all organs; all tissues from piglet 4 were positive for SVA and only 1 tissue sample from 3 piglets (nos. 2, 3, and 10) yielded negative results. Moreover, the nucleic acids of all other viruses investigated during this study were not amplified.

Sequence analysis from the 17 amplicons showed $98.8 \%-100 \%$ nt and aa similarities between each other and other isolates from Brazil available in GenBank (accession nos. KR075677 and KR075678). The SVA isolates we identified had similarities that varied from $87.4 \% \mathrm{nt}$ (GenBank accession no. EU271760) to 98.5\% nt (GenBank
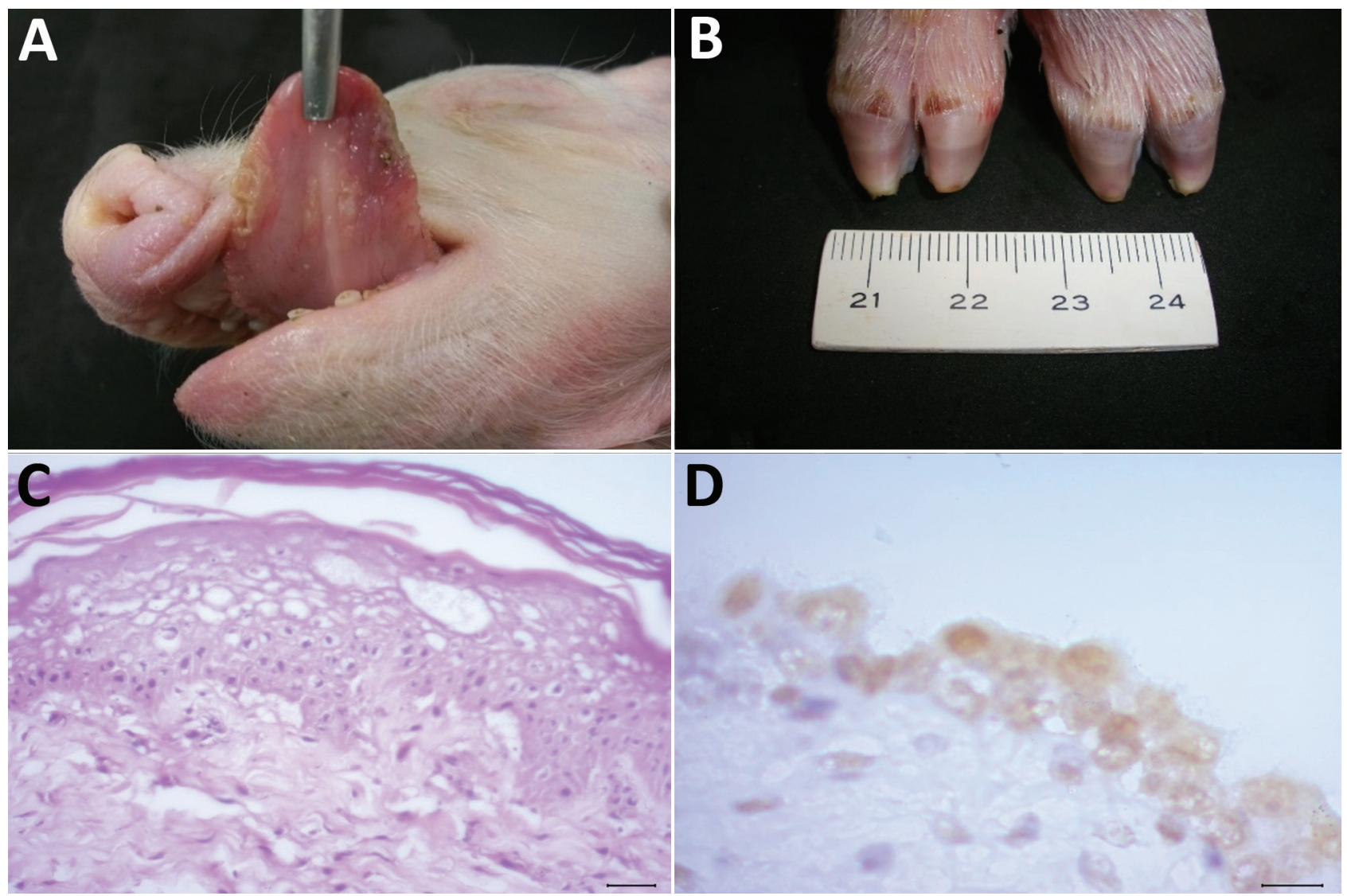

Figure 1. Pathologic alterations in piglets infected with Senecavirus A, Brazil, 2015. Gross examination shows multifocal diphtheric glossitis $(A)$ and ulcerations of the coronary band (B). Histopathologic images demonstrate ballooning degeneration of the epithelium of the tongue $(C)$ and positive immunoreactivity of the uroepithelium of the urinary bladder $(D)$ to Senecavirus $A$. Panel $B$, scale shown in centimeters; panel C, hematoxylin and eosin stain; scale bar indicates $20 \mu \mathrm{m}$; panel D, immunoperoxidase; scale bar indicates $10 \mu \mathrm{m}$. 
accession no. KC667560) and $94.4 \%$ aa (GenBank accession nos. EU271759 and EU271760) to $99.4 \%$ aa (GenBank accession no. KC667560) for isolates identified in North America. Phylogenetic analysis showed that the strains from this study (GenBank accession no. KT445973KT445977) clustered with other known isolates of SVA and were distant from other picornaviruses associated with vesicular diseases (Figure 2).

\section{Conclusions}

SVA has been associated with PIVD in pigs with vesicular lesions at the snout, coronary band, and hooves (1-3). However, findings from our investigation suggest a new clinical syndrome associated with SVA infection that resulted in disease to multiple tissues and organs of these piglets.

The patterns of the cutaneous lesions identified in this study might be similar to those of other vesicular infections of picornavirus (FMDV and SVDV), in which ballooning degeneration of epithelial cells and the formation of microvesicles are hallmarks $(14,15)$. In addition, FMDV and SVDV affect different organs of susceptible animals - the heart, lungs, lymph nodes, bone marrow, and central nervous system $(14,15)$ - suggesting a wide organ tropism of these viruses.

An interesting feature during this study was the constant immunolabelling of SVA within epithelial cells of the choroid plexus of the brain and the surrounding endothelia of blood vessels in piglets with neurologic disease. On the basis of the IHC results and molecular findings in different tissues of the brain, we theorized that the neurologic manifestations of SVA observed during this investigation might be due to early infection of the choroid plexus through alteration of the integrity of the vascular epithelium and subsequent dissemination to the adjacent neuropil. The IHC detection of SVA within the urinary epithelium of all piglets suggests that urine might be a mode of dissemination and a possible source of contamination within affected pig farms.

Another unusual finding associated with SVA infection during this study was the occurrence of diarrhea in piglets. Molecular screening did not detect any of the common enteric viral pathogens of suckling piglets. However, the IHC and reverse transcription PCR identified SVA in the small intestine of piglets with diarrhea, demonstrating the ability of SVA to replicate within the enteric epithelium.

Our results suggest that SVA is a pantropic virus that produces a multisystemic disease entity in pigs infected at an early age. The constant immunolabelling of the uroepithelium of all piglets with SVA antigens might indicate that in-pen contamination, through urine, should be considered as a possible route for the dissemination of this virus.

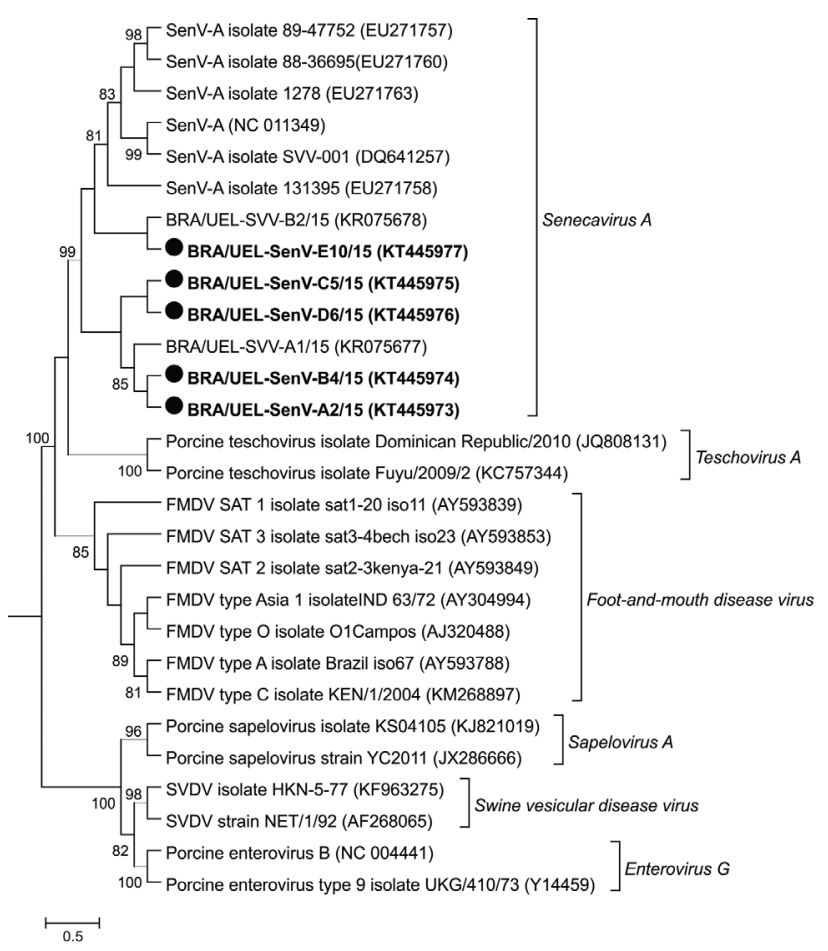

Figure 2. Phylogenetic relationship of strains of Senecavirus $A$ identified in Brazil during 2015 (black circles) and other sequences available in GenBank derived from species of picornavirus associated with vesicular disease. Maximum-likelihood phylogenetic tree construction used the Kimura 2-parameter model with $\mathrm{g}$ distribution based on the partial viral protein (VP) 3/VP1 region of the Senecavirus A genome. GenBank accession numbers are given in parentheses. Bootstrap values determined in 1,000 replication. Scale bar indicates nucleotide substitutions per site.

The following Brazilian institutes provided financial support: National Council of Scientific and Technological Development, Brazilian Federal Agency for Support and Evaluation of Graduate Education, Financing of Studies and Projects, and Araucaria Foundation. R.A.L., S.A.H., A.F.A., and A.A.A. received National Council of Scientific and Technological Development fellowships and grants.

Dr. Leme is PhD fellow at Laboratory of Animal Virology and Multi-User Animal Health Laboratory, Molecular Biology Unit, Department of Veterinary Preventive Medicine, Universidade Estadual de Londrina, Brazil. Her research interests include molecular epidemiology surveillance of emerging and reemerging viruses of swine.

\section{References}

1. Singh K, Corner S, Clark SG, Scherba G, Fredrickson R. Seneca Valley virus and vesicular lesions in a pig with idiopathic vesicular disease. J Vet Sci Technol. 2012;3:1-3.

2. Pasma T, Davidson S, Shaw SL. Idiopathic vesicular disease in swine in Manitoba. Can Vet J. 2008;49:84-5.

3. Leme RA, Zotti E, Alcântara BK, Oliveira MV, Freitas LA, Alfieri AF, et al. Senecavirus A: an emerging vesicular infection 
in Brazilian pig herds. Transbound Emerg Dis. 2015;62:603-11. http://dx.doi.org/10.1111/tbed.12430

4. Vannucci FA, Linhares DC, Barcellos DE, Lam HC, Collins J, Marthaler D. Identification and complete genome of Seneca Valley virus in vesicular fluid and sera of pigs affected with idiopathic vesicular disease, Brazil. Transbound Emerg Dis. 2015;62:589-93. http://dx.doi.org/10.1111/tbed.12410

5. Yang M, van Bruggen R, Xu W. Generation and diagnostic application of monoclonal antibodies against Seneca Valley virus. J Vet Diagn Invest. 2012;24:42-50. http://dx.doi.org/10.1177/ 1040638711426323

6. World Organization for Animal Health. Manual of diagnostic tests and vaccines for terrestrial animals 2015 [cited 2015 Mar 27]. http://www.oie.int/international-standard-setting/terrestrial-manual/ access-online/

7. Donin DG, Leme RA, Alfieri AF, Alberton GC, Alfieri AA. First report of porcine teschovirus (PTV), porcine sapelovirus (PSV) and enterovirus G (EV-G) in pig herds of Brazil. Trop Anim Health Prod. 2014;46:523-8. http://dx.doi.org/10.1007/ s11250-013-0523-z

8. Soares RM, Durigon EL, Bersano JG, Richtzenhain LJ. Detection of porcine parvovirus DNA by the polymerase chain reaction assay using primers to the highly conserved nonstructural protein gene, NS-1. J Virol Methods. 1999;78:191-8. http://dx.doi.org/10.1016/ S0166-0934(98)00177-3

9. McIntosh KA, Tumber A, Harding JC, Krakowka S, Ellis JA, Hill JE. Development and validation of a SYBR green realtime PCR for the quantification of porcine circovirus type 2 in serum, buffy coat, feces, and multiple tissues. Vet Microbiol. 2009;133:23-33. http://dx.doi.org/10.1016/j.vetmic.2008.06.010
10. Médici KC, Barry AF, Alfieri AF, Alfieri AA. Porcine rotavirus groups $\mathrm{A}, \mathrm{B}$, and $\mathrm{C}$ identified in polymerase chain reaction in a fecal sample collection with inconclusive results by polyacrylamide gel electrophoresis. J Swine Health Prod. 2011;19:146-50.

11. Molinari BL, Lorenzetti E, Otonel RA, Alfieri AF, Alfieri AA. Species H rotavirus detected in piglets with diarrhea, Brazil, 2012. Emerg Infect Dis. 2014;20:1019-22. http://dx.doi.org/10.3201/ eid2006.130776

12. Kim SY, Song DS, Park BK. Differential detection of transmissible gastroenteritis virus and porcine epidemic diarrhea virus by duplex RT-PCR. J Vet Diagn Invest. 2001;13:516-20. http://dx.doi.org/ 10.1177/104063870101300611

13. Wang L, Byrum B, Zhang Y. Detection and genetic characterization of deltacoronavirus in pigs, Ohio, USA, 2014. Emerg Infect Dis. 2014;20:1227-30. http://dx.doi.org/10.3201/eid2007.140296

14. Arzt J, Baxt B, Grubman MJ, Jackson T, Juleff N, Rhyan J, et al. The pathogenesis of foot-and-mouth disease II: viral pathways in swine, small ruminants, and wildlife; myotropism, chronic syndromes, and molecular virus-host interactions. Transbound Emerg Dis. 2011;58:305-26. http://dx.doi.org/10.1111/j.1865-1682.2011.01236.x

15. Escribano-Romero E, Jiménez-Clavero MA, Ley V. Swine vesicular disease virus. Pathology of the disease and molecular characteristics of the virion. Anim Health Res Rev. 2000;1:119-26. http://dx.doi.org/10.1017/S1466252300000104

Address for correspondence: Amauri A. Alfieri, Laboratory of Animal Virology, Department of Veterinary Preventive Medicine, Universidade Estadual de Londrina, P.O. Box 10011, 86057-970, Londrina, Parana, Brazil; email: alfieri@uel.br

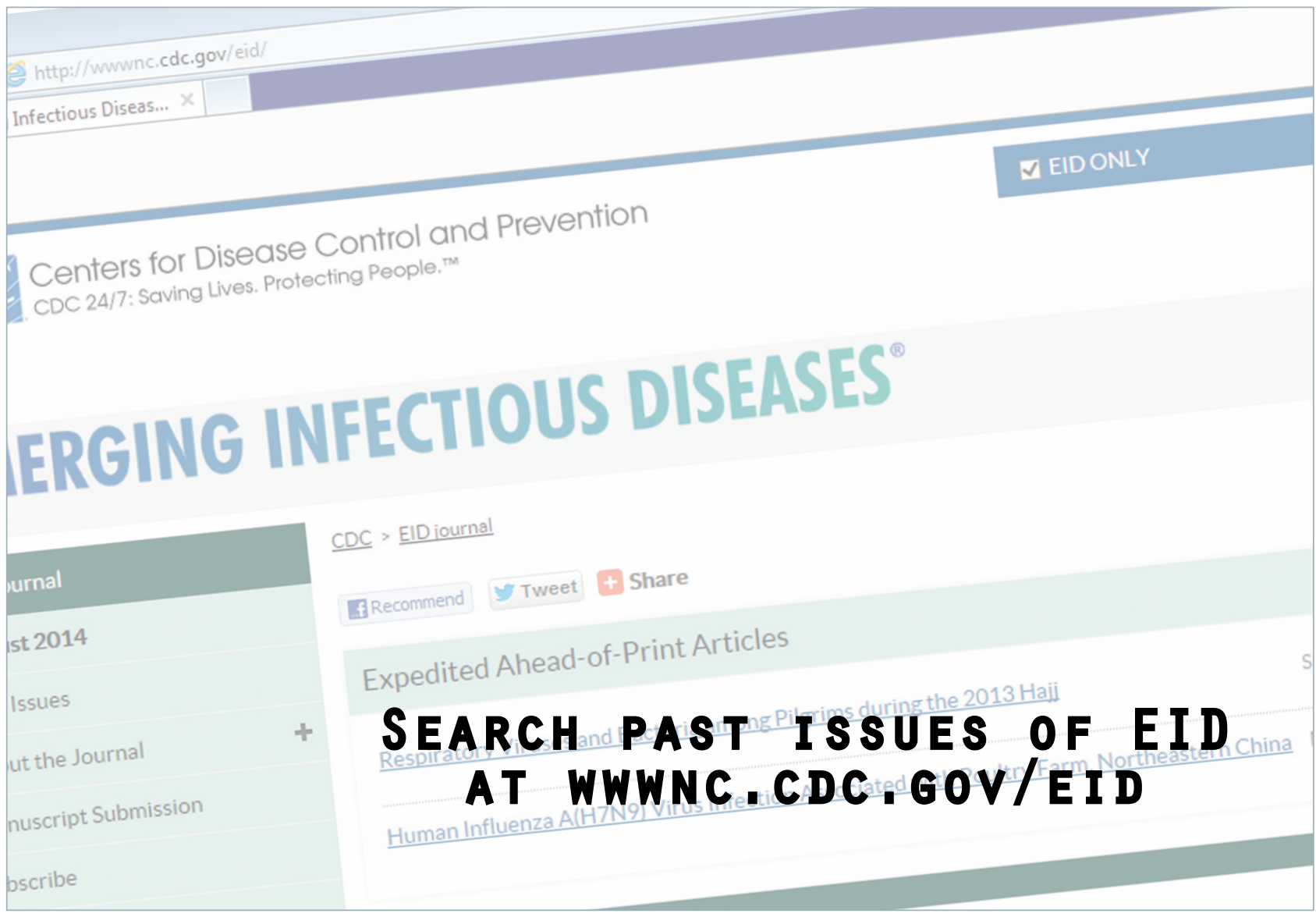

